\author{
Yuli Yanah \\ $1711059012 \mathrm{P}$ \\ FAKULTAS KOMPUTER \\ yanayuli1711059012p@mail.darmajaya.ac.id
}

\begin{abstract}
Abstrak
CV. Intra Media Bali saat ini menggunakan sistem komputerisasi yang sangat sederhana dalam mengelola data karyawan, data barang, data pembelian, data penjualan, data servis, dan data biaya operasional perusahan. Dalam pelaksanaannya masih banyak kendala yang dihadapi, tentunya apabila kendala-kendala tersebut tidak segera diperbaiki maka tidak akan mampu mengikuti perkembangan dan kebutuhan teknologi di masa akan datang. Untuk mengatasi masalah dan kendala ini perlu dikembangkan suatu sistem informasi manajemen berbasis visual basic 6.0 untuk membantu pekerjaan menjadi lebih efektif dan efisien dalam hal pengolahan data karyawan, data barang, data pembelian, data penjualan, data servis, data biaya operasional perusahaan, dan data keuangan perusahaan. Sistem informasi manajemen berbasis visual basic 6.0 memiliki beberapa kelebihan yaitu user dapat dengan mudah menginputkan data-data baik itu berupa data karyawan, data barang, data servis, dan data biaya operasional perusahaan agar lebih mempermudah dalam proses pelaporan. Dengan adanya Sistem Informasi Manajemen ini diharapkan dapat digunakan sebagai sarana untuk mengolah data-data informasi karyawan, data informasi barang, data informasi penjualan, data informasi pembelian, data informasi servis, data informasi biaya operasional, dan data informasi laba rugi perusahaan di CV. Intra Media Bali.
\end{abstract}




\section{PENGEMBANGAN SISTEM INFORMASI MANAJEMEN}

\section{INTRA MEDIA BALI}

\section{A PENDAHULUAN}

Latar Belakang CV. Intra Media Bali adalah peru- sahaan yang bergerak di dalam bidang tekno- logi khusus-nya komputer yang merupakan tempat jual beli komputer dan aksesoris kom- puter. Seiring dengan perkembangan peru- sahaan, maka data-data yang dibutuhkan oleh perusahaan semakin komplek. Pada perusa- haan ini masih dihadapkan dengan berkas- berkas laporan perusahaan yang menumpuk dan hitungan matematis secara manual. Sistem Informasi Manajemen meliputi data karyawan, penggajian karyawan, data barang dan sirkulasinya (transaksi), akuntansi sederhana sesuai kebutuhan perusahaan dan laporanlaporan yang dibutuhkan meliputi data karyawan, stok barang, dan laporan laba rugi perusahaan serta penggajian karyawan untuk menunjang perkembangan perusahaan. Sistem Informasi Manajemen pada CV. Intra Media Bali dikembangkan agar informasi manajemen pada perusahaan ter- sebut baik itu proses data gudang, data kar- yawan, laporan laba rugi perusahaan, dan penggajian karyawan dapat diolah dengan lebih teliti, efisien, cepat dan akurat. Sistem Informasi Dalam artian umum, sistem informasi merupakan interrelasi antara beberapa kom- ponen yang menyimpan, mengambil, mene- rima, memproses, dan mendistribusikan in- formasi untuk mendukung kegiatan pengam- bil keputusan, dan mengontrol sebuah orga- nisasi. Sedangkan dalam arti khusus, sistem informasi adalah perangkat lunak yang digunakan untuk meningkatkan kinerja sebuah sistem dalam menangani informasi atau data.

Sistem Informasi Manajemen Perusahaan Sistem Informasi Manajemen adalah suatu aplikasi sistem informasi untuk menge- lola data tentang data karyawan, data penggajian, data barang, dan keuntungan pada suatu perusahaan. Perangkat lunak pada peru- sahaan ini yang dirancang untuk menunjang kinerja perusahaan, mengetahui secara dini segala bentuk informasi mengenai data kar- yawan, data penggajian, data barang, dan ke- untungan perusahaan. .

\section{B SIMPULAN}

Berdasarkan hasil pengujian sistem yang dilakukan, dapat diambil kesimpulan beberapa hal antara lain : Sistem informasi manajemen ini akan mempermudah aktifitas 
kerja pada perusahaan tersebut baik dalam menangani pengolahan data karyawan, data absensi, data barang, data penjualan, data pembelian, data servis, dan data biaya operasional peru- sahaan, untuk memperoleh laporan keun- tungan perusahaan dalam waktu yang cepat dan perhitungan yang lebih akurat guna memajukan kinerja perushaan. Dengan menggunakan sistem ini, pro- ses penginputan data akan menjadi lebih ce- pat dan mempersingkat waktu dalam penca- rian data-data pada perusahaan. Dengan sis- tem ini pimpinan dapat dengan mudah mengetahui seluruh laporan- laporan yang ada pada perusahaan, sehingga pimpinan dapat dengan segera mengambil kebijak- sanaan guna memajukan perusahaan

2 Kualitas Informasi pada Sistem Informasi Manajemen dalam Pelayanan Jaminan Kesehatan Sistem informasi dapat dimanfaatkan untuk kegiatan pelayanan data dan informasi dengan lebih produktif, transparan, tertib, cepat, mudah, akurat, terpadu, aman dan efisien, khususnya membantu dalam memperlancar dan mempermudah pembentukan kebijakan dalam meningkatkan sistem pelayanan kesehatan khususnya dalam bidang penyelenggaraan Rumah Sakit di Indonesia.penelitian ini mengkaji penggunaan output serta laporan SIMRS khususnya pada pelayanan Jaminan Kesehatan (BPJS) serta pemanfaatannya bagi pimpinan dan pihak manajemen. Disarankan proses input data harus dibenahi. Petunjuk atau arahan manual SIM semestinya dibuat dan dibagikan ke seluruh operator.

Sistem informasi dapat dimanfaatkan untuk kegiatan pelayanan data dan informasi dengan lebih produktif, transparan, tertib, cepat, mudah, akurat, terpadu, aman dan efisien, khususnya membantu dalam memperlancar dan mempermudah pembentukan kebijakan dalam meningkatkan sistem pelayanan kesehatan khususnya dalam bidang penyelenggaraan Rumah Sakit di Indonesia Sistem Informasi di Rumah Sakit sangat diperlukan untuk mempermudah akses pelayanan, sehingga dapat berjalan lebih optimal. Komitmen Rumah Sakit untuk memberikan pelayanan kesehatan yang bermutu, maka Rumah Sakit dituntut untuk mengembangkan dirinya menjadi suatu lembaga yang mampu bersaing dalam pelayanan perumahsakitan dan mempunyai keunggulankomparatif. Untuk itu diperlukan perencanaan dan pengembangan yang komprehensif untuk menjadi Rumah Sakit Umum kelas B. 
Sistem Informasi di Rumah Sakit sangat diperlukan untuk mempermudah akses pelayanan, sehingga dapat berjalan lebih optimal. Komitmen Rumah Sakit untuk memberikan pelayanan kesehatan yang bermutu, maka Rumah Sakit dituntut untuk mengembangkan dirinya menjadi suatu lembaga yang mampu bersaing dalam pelayanan perumahsakitan dan mempunyai keunggulan komparatif. Untuk itu diperlukan perencanaan dan pengembangan yang komprehensif untuk menjadi Rumah Sakit Umum kelas Sistem Informasi Manajemen Puskesmas (Simpuskesmas) berbasis Cloud Computing

Puskesmas-Puskesmas di Kabupaten Demak, bahwa Puskesmas-Puskesmas ini tiap harinya melayani puluhan pasien yang datang. Saat ini sistem pengolahan data pasien tiap bagian masih dikerjakan dengan cara sistem manual atau belum memanfaatkan sistem informasi Puskesmas. Dengan masih digunakannya sistem manual dan beberapa puskesmas sudah menggunakan Simpuskesmas, maka muncul berbagai permasalahan dalam pengolahan data pasiennya. Masalah-masalah ini diantaranya adalah tingginya tingkat kesalahan dalam pengolahan data pasien (data pendaftaran, data pemeriksaan, data rujukan, dan data laboratorium) dan lambatnya proses pelayanan pasien misalnya pendataan dan pencarian data pasien. Masalah lain lagi yaitu puskesmaspuskesmas yang sudah menggunakan Simpuskesmas tdak mempunyai kseragaman system, karena tiap Puskesmas melakukan swadaya sendiri-sendiri untuk pengadaan SIMPUS. Penggunaan Simpuskesmas dengan teknologi komputer untuk pengolahan data pasien sangat diperlukan, karena dapat memberikan beberapa keuntungan dan kemudahan dalam pelayanan pasien antara lain: mempercepat pelayanan, informasi yang lebih akurat, pencarian data lebih cepat, pembuatan laporan yang lebih cepat serta keseragaman Sistem Informasi Manajemen Puskesmas di wilayah Kabupaten Demak.. Dengan adanya program Simpuskesmas berbasis cloud computing kinerja Puskesmas dapat ditingkatkan, sehingga kualitas dan mutu pelayanan menjadi meningkat. Demak merupakan kabupaten yang mempunyai banyak puskesmas. Pada puskesmas yang ada di Kabupaten Demak terdapat beberapa bagian, antara lain bagian Balai Pengobatan (BP) yang khusus menangani orang sakit biasa, bagian Kesehatan Ibu dan Anak (KIA) yang khusus menangani bayi dan ibu hamil, bagian Gigi yang khusus menangani kesehatan gigi dan mulut, dan masih banyak 
lagi bagian lainnnya. Berdasarkan identifikasi analisis situasi yang dilakukan di Puskesmas- Puskesmas di Kabupaten Demak, bahwa Puskesmas-Puskesmas ini tiap harinya melayani puluhan pasien yang datang. Saat ini sistem pengolahan data pasien tiap bagian masih dikerjakan dengan cara sistem manual atau belum memanfaatkan sistem informasi Puskesmas. Dengan masih digunakannya sistem manual, maka muncul berbagai permasalahan dalam pengolahan data pasiennya. Masalahmasalah ini diantaranya adalah tingginya tingkat kesalahan dalam pengolahan data pasien (data pendaftaran, data pemeriksaan, data rujukan, dan data laboratorium) dan lambatnya proses pelayanan pasien misalnya pendataan dan pencarian data pasien. Penggunaan komputer untuk pengolahan data pasien sangat diperlukan, karena dapat memberikan beberapa keuntungan dan kemudahan dalam pelayanan pasien antara lain: mempercepat pelayanan, informasi yang lebih akurat, dan pencarian data lebih cepat. Dengan adanya program berbasis cloud computing kinerja Puskesmas dapat ditingkatkan, sehingga kualitas dan mutu pelayanan menjadi meningkat.

Dari penelitian ini dapat diambil beberapa kesimpulan, yaitu: Sistem Informasi Manajemen (Simpuskesmas) Berbasis Cloud
Computing merupakan Simpuskesmas yang dulu dalam penerapannya menggunakan client server dirubah ke Simpuskesmas yang di upload di web sehingga puskesmaspuskesmas di Kabupaten Demak dapat mengakses SIMPUS tersebut melalui internet. Setiap Puskesmas di Kabupaten Demak apabila ingin menggunakan SIMPUS wajib memasukkan username dan password masing- masing. Dalam Simpuskesmas yang berbasis cloud computing ini, setiap puskesmas mempunyai Username dan password sendiri- sendiri. Setelah masuk ke Simpuskesmas, setiap puskesmas dapat melakukan kegiatan administratif dan pelayanan ke pasien sehari- hari. Dari SIMPUS ini diharapkan akan mempermudah pihak Puskesmas untuk kegiatan administratif, dan bagi pihak DKK akan lebih mudah mendapatkan semua laporan dari setiap puskesmas di Kabupaten Demak tanpa harus menunggu laporan dari pihak puskesmas.

PT. Kapuas Jaya Anugerah merupakan suatu perusahaan jasa di bidang pembangunan dan infrastruktur (kontraktor).

Proses pelayanan jasa dengan penyampaian informasi terkait perusahaan masih dilakukan secara konvensional. Oleh karena itu diperlukanlah konsep teknologi berbasis 
computer dalam sistem informasi manajemen untuk membantu PT. Kapuas Jaya Anugerah dalam melaksanakan proses bisnis perusahaan. Sistem dibangun dengan menerapkan teknik responsive design sehingga tampilan web dapat menyesuaikan dengan besarnya luasan area browser yang digunakan oleh user. Pendekatan yang digunakan dalam penelitian adalah pendekatan terstruktur yang menggunakan beberapa alat bantu dan teknik pengerjaan, seperti flowchart, diagram arus data (DFD), diagram relasi (ERD) dan perancangan antarmuka sistem. Pengujian sistem menggunakan metode UAT. Sistem informasi manajemen PT. Kapuas Jaya Anugerah mampu mengelola data yang berkaitan dengan permintaan barang, permintaan dana, persetujuan permintaan barang, persetujuan permintaan dana, pengiriman barang, pengiriman dana, hingga pada laporan permintaan barang dan dana. Hasil dari Sistem Informasi Manajemen PT. Kapuas Jaya Anugerah, diharapkan mampu membantu dalam pengolahan informasi perusahaan.

Teknologi informasi berperan penting dalam menjalankan suatu organisasi, perusahaan, maupun institusi. Penggunaan teknologi informasi diharapkan dapat menciptakan akurasi, kecepatan dan kelengkapan dalam sebuah system dalam perusahaan. Selain itu terdapat juga kemudahan dalam penyimpanan, pengorganisasian dan pengambilan terhadap berbagai data. Di dukung dengan perangkat lunak dan perangkat keras yang tepat, maka perusahaan dapat membangun system informasi manajemen yang handal dan berpengaruh terhadap kinerja perusahaan dalam menjalankan usahanya. PT. Kapuas Jaya Anugerah merupakan suatu perusahaan jasa di bidang pembangunan dan infrastuktur (kontraktor). Dalam menjalankan usaha jasanya, proses

administrasi perusahaan belum menggunakan perangkat lunak khususnya berupa sistem informasi manajemen. Proses pelayanan jasa dengan penyampaian informasi terkait perusahaan, masih dilakukan secara konvensional yaitu perusahaan menyediakan staff di bagian pelayanan konsumen front-liner, yang bertugas memberikan informasi kepada konsumen baik melalui telepon maupun konsumen yang secara langsung mengunjungi perusahaan. Selain dengan front-liner, media informasi lainnya yang digunakan yaitu dengan membuat buku profil perusahaan dan brosur pelayanan jasa, dimana informasi ini hanya akan didapat jika konsumen berkunjung ke kantor. Dalam 
era teknologi informasi yang berkembang sangat pesat, proses administrasi perusahaan dan pelayanan informasi bagi konsumen dapat dilakukan cepat, mudah dan akurat. Untuk itu dinilai perlu bagi PT. Kapuas Jaya Anugerah untuk membangun suatu sistem informasi dan manajemen perusahaannya. Proses administrasi pada perusahaan Kapuas jaya anugerah ini ditangani oleh staf dan dilakukan secara rutin pada setiap akhir bulan. Proses pengelolaan data pada perusahaan ini masih terkomputerisasi secara sederhana, dimana semua file pekerjaan disimpan dalam folder-folder yang dibuat sendiri oleh staf perusahaan dalam format excel (*xls) dan word $(*$ doc), dan belum menunjukan kepada Database Management System (DBMS).Dengan kondisi seperti ini, staf administrasi harus membuat surat-surat, rekapitulasi data, dan member informasi tentang perusahaan secara manual. Ini dirasakan tidak efisien dalam menjalankan bisnis perusahaan

\section{DAFTAR PUSTAKA}

[1] Komputer, Wahana. 2003. Pemrograman Visual Basic 6.0, Yogyakarta:Penerbit Andi

[2] Kadir. Abdul. 2003. Pengenalan Sistem Informasi. Yogyakarta:Penerbit Andi. karena diperlukan waktu yang lama dalam pengerjaannya. Sistem informasi dan manajemen dapat melakukan penyimpanan dan pengolahan data pada database dengan menggunakan DBMS. DBMS yang dimaksud yaitu sebuah program (software) yang dibuat agar mempermudah dan mengefisienkan pekerjaan dalam pemasukan, pengeditan, penghapusan, serta pengambilan data - data perusahaan pada database. Sistem ini berisikan bagaimana perusahaan ini akan melakukan proses pengiriman dokumen, Sehingga pihak perusahaan dapat melaksanakan pekerjaannya dengan cepat. Pada sistem ini pun mencakup tanda tangan digital sehingga pihak direksi tidak diwajibkan menandatangani setiap surat dengan cara manual. Pada proses penandatangan digital ini kesahan tanda tangan tersebut dapat dibuktikan dengan cara mengarsipkan dokumen tersebut

[3] Yuswanto. 2003. Pemrograman Client Server Microsoft Visual Basic 6.0, Jakarta:Penerbit Prestasi Pustaka.

[4] Kurniawan. Bagus. 2004. Sistem Informasi Manajemen Dengan Visual Basic 6.0, Yogyakarta:Penerbit Andi. 
Nilai Informasi
a. Kemudahan dalam memperolehnya
b. Bersikap luas dan lengkap
c. Memperhatikan ketelitian (accuracy)
d. Kecocokan dengan pengguna (relevance)
e. Ketepatan waktu (timesline)
f. Kejelasan (clarity)
g. Keluwesan
h. Dapat dibuktikan (bukan prasangka/perkiraan)
i. Dapat diukur

\section{Mutu Informasi}
a. Control sistem untuk mengeliminir kesalahan
b. Pemeriksaan internal \& eksternal
c. Penambahan batas ketelitian data
d. Feedback dari pemakai untuk menilai kesalahan yang mungkin terjadi

Biaya Informasi
a. Biaya perangkat keras
b. Biaya analisis perancangan \& pelaksanaan sistem
c. Biaya tempat \& lingkungan
d. Biaya perubahan (perubahan metode)
e. Biaya operasi 


\section{KONSEP DASAR MANAJEMEN}

- Definisi Manajemen

a. Pengelolaan kegiatan untuk menjalankan tugas \& fungsi serta tujuan suatu organisasi

b. Proses pemanfaatan sumberdaya yang tersedia untuk mencapai tujuan.

- Kegiatan Dalam Manajemen

a. Perencanaan, Pengendalian, Pengawasan, Pengambilan keputusan

b. Sumber daya

- Manusia, Material, Moal

- Informasi

\section{PROSES MANAJEMEN}

- Tingkatan Kegiatan Manajemen

- Perencanaan \& pengedalian operasional

Low, Level, Manajemen

- Perencanaa Taktis \& Pengenalian Manajemen

- Midle, level, Manajemen

Manajemen Informasi

- Level manajemen \& Pengguna informasi

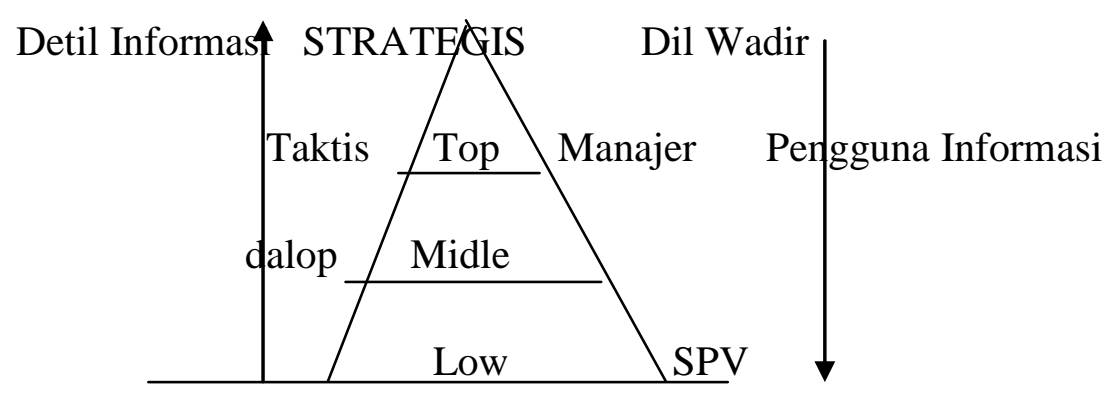


Definisi Sistem Informasi Manajemen

A. Terminologi Frase

Kegiatan yang dilakukan oleh sekelompok unsure dalam sebuah organisasi yang saling terkait dalam usaha memecahkan suatu masalah dengan memanfaatkan sumber daya manajemen sehingga sampai pada sebuah pemberian informasi untuk mendukung pengambilan keputusan.

B. James Altur (1992) Manajemen Perspektive

Kombinasi antar prosedur kerja, Informasi, Orang dan teknologi informasi yang iorganisasikan untuk mencapai tujuan dalam sebuah informasi

Kesamaan Dari Berbagai Teori
a. Produk : Informasi
b. Tujuan : menghasilkan informasi untuk berbagai pihak
c. Fungsi : Pengelolaan sumber-sumber masukan hingga menjadi informasi
d. Sumber Masukan : Data \& Atau Informasi

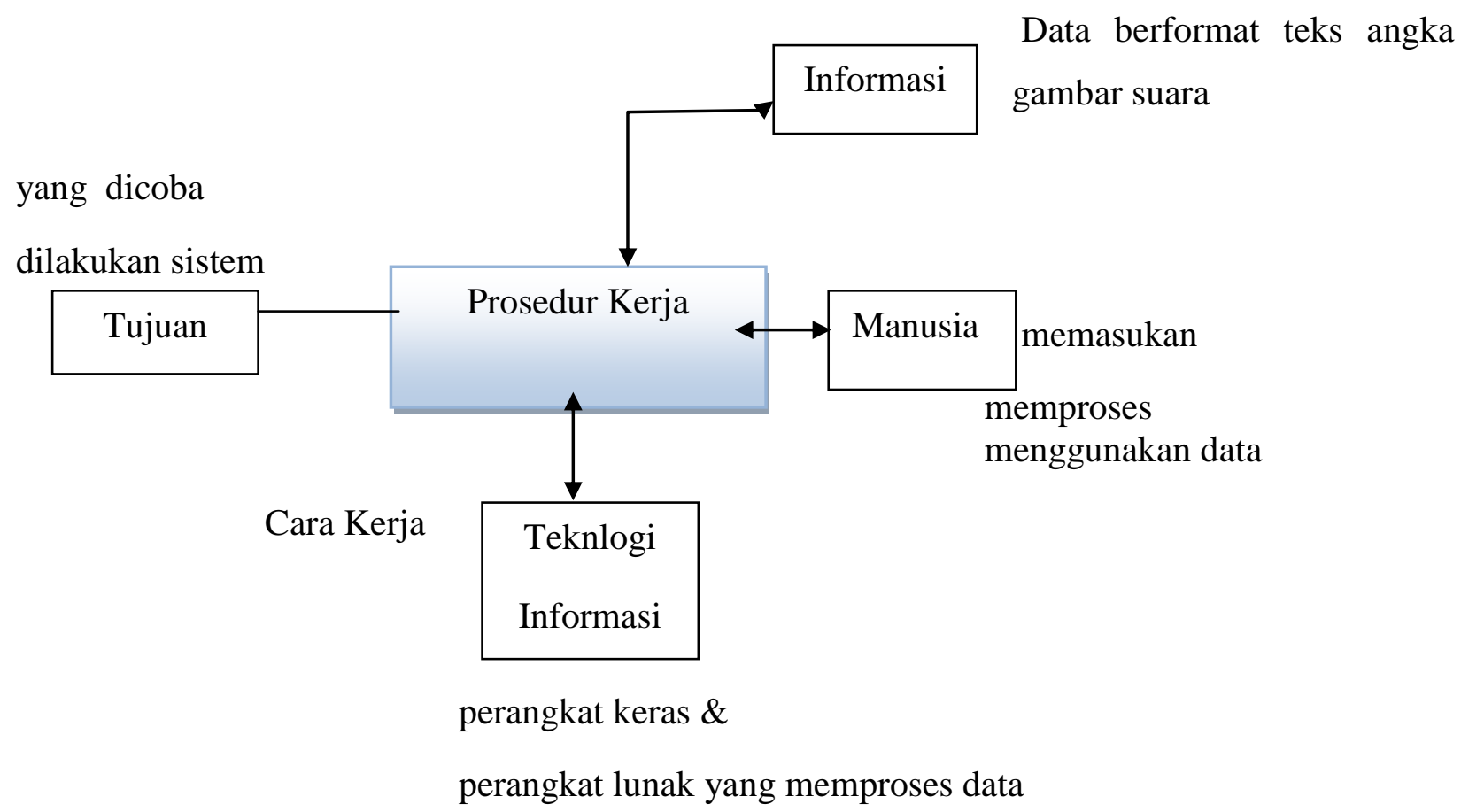


* Pengaruh Pengelolaan SI dalam Organisasi

- Cost Of running

- Penekanan biaya, menaikan profit

- Customer Service

- Kemudahan pelayanan meningkatkan performa layanan

- Manajement Prosess

-. Tertib tata laksana pengelolaan organisasi

* Perkembangan Sistem

Dalam Perkembangannya ternyata sim tidak hanya di implementasikan pada industry atau pabrik namun sistem tsb ternyata sesuai juga untuk dipakai oleh organisasi lainnya.

* Proses Sistem Informasi Manajemen

Bila dilihat dari segi pengelolaan data sim mengumpulkan semua data dari unit kerja yang terkait langsung dilapangan. Data \& informasi yang dikumpulkan selanjutnya disimpan dalam file database untuk diproses lebih lanjut dalam memproses inisim memiliki kaidah seperti privhai kecurut yang artinya sim server pusat.

MIS/SIM Server pusat

\begin{tabular}{|c|}
\hline Ka. Departemen \\
\hline Ka.Cabang \\
\hline Ka. Devisi \\
\hline Ka.Bagian
\end{tabular}


Fakultas Komputer

Yuli Yanah

TUGAS-3 88675543

Manajemen Informsasi

A. Jenis-jenis utama sumber daya

- Manusia

- Material

- Mesin

- Uang

- Data dan Informasi

Manajemen informasi $=$ seluruh aktiitas untuk memperoleh informasi menggunakannya seefektif mungkin dan membuangnya pada saat yang tepap 
Fakultas Komputer

Yuli Yanah

TUGAS-3 88675543 